\title{
Nutritional Characterization of Some Selected Actinomycetes
}

\author{
BARBARA LA T. PROSSER AND NORBERTO J. PALLERONI \\ Department of Chemical Research, Hoffmann-La Roche, Inc., Nutley, New Jersey 07110
}

\begin{abstract}
Strains of several genetically important Streptomyces species and four strains of Nocardia mediterranei were screened for nutritional properties by using 150 different organic compounds. The methodology for an extensive nutritional analysis of actinomycetes is described, and the results are discussed on the basis of their taxonomic and ecological implications.
\end{abstract}

Actinomycetes constitute a substantial proportion of the microbial flora of soils. Among the strains that can be very easily isolated by conventional bacteriological techniques, the members of the economically important genus Streptomyces are particularly abundant and diverse and, consequently, a large number of species have been described. In the 8th edition of Bergey's Manual of Determinative Bacteriology 463 are described (9), and many more names could be added to the list. The assignment of a new strain to a given species described in the literature is often an exceedingly difficult task, and this unsatisfactory state of affairs perhaps can be mainly attributed to the formidable difficulty of defining the precise limits of species in this group of procaryotic organisms.

The numbers of actinomycetes in soil increase substantially after addition of organic matter. This, added to the enormous diversity of morphological and physiological attributes already known in the group, prompted us to explore the possibility of using an extensive nutritional analysis as a means of facilitating the phenotypic characterization of strains, thus providing a basis for their classification. A similar type of analysis proved of substantial help in the classification of other groups of nutritionally versatile organisms, such as the pseudomonads (13). The present communication describes the methodology used and an extensive nutritional characterization of several Streptomyces species and strains of Nocardia mediterranei. Since these organisms have been subjected to genetical analyses in other laboratories, results of our nutritional studies may prove useful for mapping purposes.

\section{MATERIALS AND METHODS}

Microbial strains. To facilitate the presentation of the results, the 25 strains used in our work have been designated with letters from $a$ to $y$. Strains $a, g$, $h, i, j, k, n, o, p, q, r, s, t, u$, and $v$ were received from D. A. Hopwood; the others were purchased from the American Type Culture Collection. Further details are given in Table 1.
Preparation of inocula for the nutritional screening. The cultures were grown on agar plates of a variety of culture media, including the medium of Hickey and Tresner (4), tomato medium, Thermoactinomyces fermentation medium, Difco ISP no. 2 , and yeast-malt medium [tomato medium: tomato paste, $2 \%$; glucose, $1 \% ; \mathrm{K}_{2} \mathrm{HPO}_{4}, 0.1 \% ; \mathrm{CaCO}_{3}, 0.2 \%$; agar, $1.5 \%$; $\mathrm{pH} 6.8$ to 7.3. Thermoactinomyces fermentation medium: tryptone (Difco), $5 \mathrm{~g}$; yeast extract, $2 \mathrm{~g}$; Soytone (Difco), $2 \mathrm{~g}$; white potato dextrin (soluble starch), $10 \mathrm{~g}$; D-mannitol, $5 \mathrm{~g}$; $\mathrm{MgSO}_{4}, 0.2 \mathrm{~g}$; ferrous ammonium sulfate, $10 \mathrm{mg} ; \mathrm{ZnCl}_{2}, 2.1 \mathrm{mg} ; \mathrm{MnCl}_{2}, 1.8$ $\mathrm{mg} ; \mathrm{CuSO}_{4}, 0.2 \mathrm{mg} ; \mathrm{Co}\left(\mathrm{NO}_{3}\right)_{2}, 0.5 \mathrm{mg} ; \mathrm{H}_{3} \mathrm{BO}_{3}, 0.6 \mathrm{mg}$; distilled water, 1 liter; $\mathrm{pH}$ 7.2. Yeast-malt medium: yeast extract, $0.3 \%$; malt extract, $0.3 \%$; peptone, $0.5 \%$; glucose, $1 \%$; agar $2 \%$; $\mathrm{pH} 6.7$ to 7.8 .] Spores, or vegetative growth in cases of poor sporulation, were harvested with an inoculating loop, and suspended in sterile distilled water. The suspensions were washed, and one drop of each suspension of washed cells was used as inoculum of the agar media, each of which contained a single carbon source.

Nutritional screening. The basal mineral medium described by Palleroni and Doudoroff (8) was used in all cases. This medium contains $0.033 \mathrm{M}$ phosphate buffer (Na-K) (pH 6.8), 0.1\% $\mathrm{NH}_{4} \mathrm{Cl}, 0.05 \% \mathrm{MgSO}_{4}$. $7 \mathrm{H}_{2} \mathrm{O}, 0.005 \%$ ferric ammonium citrate, and $0.0005 \%$ $\mathrm{CaCl}_{2}$. For strain $h$, this medium was supplemented with cystine, methionine, and threonine $(50 \mu \mathrm{g}$ of each per $\mathrm{ml}$ ). The medium was solidified with $2 \%$ purified agar (Difco). A total of 150 organic compounds were tested for their capacity to serve as carbon and energy sources for growth. Each carbon source was added aseptically from a filter-sterilized concentrated solution to a portion of sterile basal mineral agar, to a final concentration of $0.1 \%$. Exceptions were geraniol and naphthalene, which were not incorporated into the agar, but placed instead in the lid of the petri dish.

Various strains of actinomycetes can attack agar to a certain extent, and give appreciable growth in media without an added carbon source. The purified brand of agar gave a minimum background growth, but, even so, one of our strains ( $S$. coelicolor strain $a$ ) grew noticeably more than the others in the unsupplemented medium. For this strain, the data obtained on the agar medium were rechecked by growth in liquid medium. The medium was dispensed in fractions of 10 $\mathrm{ml}$ in 50-ml Erlenmeyer flasks.

The inoculated media were incubated at $28^{\circ} \mathrm{C}$. The flasks with liquid media were shaken with vigorous 
TABLE 1. Actinomycete strains used in the nutritional screening

\begin{tabular}{|c|c|c|c|}
\hline Species & $\begin{array}{l}\text { Notation } \\
\text { used in the } \\
\text { tables }\end{array}$ & $\begin{array}{c}\text { Hoffmann-La } \\
\text { Roche collection } \\
\text { no. }\end{array}$ & Original designation \\
\hline Streptomyces coelicolor & $a$ & $2520 \mathrm{~A}$ & Hopwood 1147 \\
\hline$\ldots \ldots \ldots \ldots \ldots \ldots \ldots \ldots \ldots$ & $b$ & $2525 \mathrm{~A}$ & ATCC 3355 \\
\hline$\ldots \ldots \ldots \ldots \ldots \ldots \ldots \ldots$ & $c$ & $2526 \mathrm{~A}$ & ATCC 10147 \\
\hline$\ldots \ldots \ldots \ldots \ldots \ldots \ldots \ldots$ & $d$ & 2527A & ATCC 19832 \\
\hline$\ldots \ldots \ldots \ldots \ldots \ldots$ & $e$ & 2534A & ATCC 23899 \\
\hline S. coelicolor subsp. flavus & $f$ & 2528A & ATCC 19894 \\
\hline 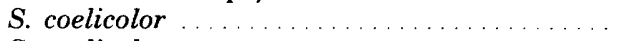 & $\boldsymbol{g}$ & 2733A & Hopwood 1157 \\
\hline S. coelicolor ... & $h$ & $2741 \mathrm{~A}$ & Hopwood J650 ${ }^{a}$ \\
\hline S. violaceoruber & $i$ & $2732 \mathrm{~A}$ & Hopwood 1151 \\
\hline S. parvulus . . . . . . . . . . . & $j$ & $2734 \mathrm{~A}$ & Hopwood 2266 \\
\hline S. glaucescens $\ldots \ldots \ldots \ldots \ldots \ldots \ldots \ldots$ & $k$ & $2522 \mathrm{~A}$ & Hopwood 1472 \\
\hline S. glaucescens & $l$ & $2529 \mathrm{~A}$ & ATCC 23622 \\
\hline S. glaucescens & $m$ & $2530 \mathrm{~A}$ & ATCC 19905 \\
\hline$\ldots \ldots \ldots \ldots$ & $n$ & $2523 \mathrm{~A}$ & Hopwood 1326 \\
\hline$\ldots \ldots \ldots \ldots \ldots \ldots \ldots \ldots \ldots$ & $o$ & $2524 \mathrm{~A}$ & Hopwood 1459 \\
\hline$\ldots \ldots \ldots \ldots \ldots \ldots \ldots$ & $p$ & $2735 \mathrm{~A}$ & Hopwood 2248 \\
\hline$\ldots \ldots \ldots \ldots \ldots$ & $q$ & $2736 \mathrm{~A}$ & Hopwood 2249 \\
\hline S. rimosus .... & $r$ & 2737A & Hopwood 2250 \\
\hline S. rimosus ... & $s$ & $2738 \mathrm{~A}$ & Hopwood 2251 \\
\hline S. rimosus ... & $t$ & $2839 \mathrm{~A}$ & Hopwood 2252 \\
\hline S. rimosus . . & $u$ & $2740 \mathrm{~A}$ & Hopwood 2253 \\
\hline Nocardia mediterranei ... & $v$ & 2521A & Hopwood 1276 \\
\hline N. mediterranei . . . . & $w$ & 2531A & ATCC 21411 \\
\hline N. mediterranei & $x$ & $2532 \mathrm{~A}$ & ATCC 21271 \\
\hline$\ldots \ldots \ldots \ldots \ldots \ldots \ldots \ldots \ldots$ & $y$ & 2533A & ATCC 27643 \\
\hline
\end{tabular}

${ }^{a}$ Mutant agaA cysD mthB obtained from strain $a$.

rotary motion $(270 \mathrm{rpm})$. Growth was estimated visually on the solid and in liquid media after 7 and 21 days of incubation, and it was recorded as follows: -, no growth; + , abundant growth; and \pm , scanty growth. All growth experiments were repeated at least once more for those compounds giving questionable growth.

All strains were tested for autotrophic growth in mineral medium in contact with an atmosphere of $52 \%$ hydrogen, $8 \%$ oxygen, $5 \%$ carbon dioxide, and $35 \%$ nitrogen gases.

\section{RESULTS}

The compounds utilized by all strains for growth were the following: glucose, mannose, fructose, maltose, lactose, starch, gluconate, succinate, fumarate, L-malate, citrate, $\alpha$-ketoglutarate, pyruvate, glycerol, D-arabitol, mannitol, $\beta$ alanine, L-serine, L-threonine, L-glutamate, L-arginine, and L-ornithine.

Compounds not used by the strains as sole sources of carbon were: carbon dioxide, $D$-fucose, melezitose, inulin, cellulose, mucate, formate, isobutyrate, caproate, heptanoate, caprylate, pelargonate, caprate, oxalate, glutarate, tartronate, D-tartrate, L-tartrate, glycollate, citraconate, itaconate, dulcitol, methanol, ethanol, $n$-propanol, isobutanol, secondary butanol, tertiary butanol, geraniol, D-mandelate, L-mandelate, benzoate, $o$-hydroxybenzoate, $m$-hydroxybenzoate, phthalate, naphthalene, phenol, testoster- one, $\alpha$-aminobutyrate, $\alpha$-aminovalerate, $\delta$-aminovalerate, $\mathrm{D}$-tryptophan, anthranilate, $p$-aminobenzoate, methylamine, butylamine, secondary butylamine, tertiary butylamine, isobutylamine, $\alpha$-amylamine, benzylamine, tryptamine, creatine, nicotinate, isonicotinate, and trigonelline.

Compounds which inhibited background growth of $S$. coelicolor strain $a$ in basal mineral agar were the following: formate, isobutyrate, caproate, heptanoate, caprylate, pelargonate, caprate, oxalate, DL-tartrate, D-malate, itaconate, benzoate, $o$-hydroxybenzoate, $m$-hydroxybenzoate, phenylacetate, phenol, $\alpha$-aminobutyrate, $\alpha$-aminovalerate, D-tryptophan, anthranilate, $p$ aminobenzoate, tryptamine, and isonicotinate.

The compounds utilized by some of the strains are listed in Table 2. In this table the strains of the first, second, and fifth columns have been grouped according to their original designation as given in Table 1 ( $S$. coelicolor, $S$. violaceoruber, and $S$. lividans, respectively). The nomenclature of these strains and their correct species assignment will be analyzed in the Discusion.

\section{DISCUSSION}

Waksman (14) refers to his own paper of 1919 as the first report of an attempt to investigate 
TABLE 2. Compounds utilized by a fraction of the strains ${ }^{a}$

\begin{tabular}{|c|c|c|c|c|c|c|c|}
\hline Substrate & $\begin{array}{c}\text { Strains } \\
a \text { to } h^{b} \\
\text { (8 strains) }\end{array}$ & $\begin{array}{l}\text { Strain } i^{b} \\
\text { (1 strain) }\end{array}$ & $\begin{array}{c}\text { S. parvu- } \\
\text { lus } \\
\text { (1 strain) }\end{array}$ & $\begin{array}{c}\text { S. glau- } \\
\text { cescens } \\
\text { (3 strains) }\end{array}$ & $\begin{array}{l}\text { Strain } n^{b} \\
\text { (1 strain) }\end{array}$ & $\begin{array}{l}\text { S. rimosus } \\
\text { (7 strains) }\end{array}$ & $\begin{array}{l}\text { N. mediter- } \\
\text { ranei } \\
\text { (4 strains) }\end{array}$ \\
\hline Ribose & 8 & 1 & 1 & 3 & 1 & $6(s)$ & $3(v)$ \\
\hline$\ldots \ldots \ldots \ldots$ & 8 & 1 & 1 & 3 & 1 & $5(o, r)$ & 4 \\
\hline D-Arabinose $\ldots \ldots \ldots \ldots$ & 0 & 0 & 0 & 0 & 0 & $\begin{array}{l}2(o, p, s \\
t, u)\end{array}$ & 4 \\
\hline L-Arabinose & 8 & 1 & 1 & 3 & 1 & $5(p, r)$ & 4 \\
\hline L-Fucose $\ldots \ldots \ldots \ldots \ldots$ & 0 & 0 & 0 & 0 & 0 & $\begin{array}{c}1(o, p, q \\
\quad s, t, u)\end{array}$ & 4 \\
\hline L-Rhamnose & $7(e)$ & 1 & 1 & 3 & 1 & $\begin{array}{c}1(o, p, r \\
\quad s, t, u)\end{array}$ & 4 \\
\hline$\ldots \ldots \ldots$ & 8 & 1 & 1 & $2(m)$ & 1 & 7 & 4 \\
\hline$\ldots \ldots \ldots$ & 0 & 0 & 0 & 0 & 0 & $\begin{array}{l}1(o, p, r, s \\
t, u)\end{array}$ & 0 \\
\hline Sucrose $\ldots \ldots \ldots \ldots \ldots \ldots$ & 0 & 0 & 0 & 0 & 0 & $\begin{array}{l}1(o, p, r, s, t \\
u)\end{array}$ & 4 \\
\hline Cellobiose & 8 & 1 & 1 & 3 & 1 & $6(r)$ & 4 \\
\hline$\ldots \ldots \ldots$ & $6(a, e)$ & 1 & 1 & $1(k, m)$ & 0 & $6(0)$ & $1(v, w, x)$ \\
\hline Salicin ... & 8 & 1 & 1 & 3 & 1 & $4(o, p, s)$ & 4 \\
\hline Raffinose & $\begin{array}{l}2(a, c, d \\
\quad e, f, g)\end{array}$ & 1 & 0 & 0 & 0 & $6(0)$ & $1(w, x, y)$ \\
\hline 2-Ketogluconate $\ldots \ldots \ldots$ & $\begin{array}{l}1(a, b, c, d, e, \\
\quad g, h)\end{array}$ & 0 & 0 & 0 & 0 & 0 & $1(v, w, x)$ \\
\hline Saccharate $\ldots \ldots \ldots \ldots$ & $3(a, e, f, g, h)$ & 1 & 1 & 0 & 1 & 0 & $1(v, w, x)$ \\
\hline Lactobionate ........... & $6(e, g)$ & 1 & 1 & 3 & 1 & $\begin{array}{l}2(o, p, r \\
\quad s, t)\end{array}$ & 4 \\
\hline Glucosamine & $7(f)$ & 1 & 1 & 3 & 1 & 7 & 4 \\
\hline Acetate $\ldots \ldots \ldots \ldots$ & 8 & 1 & 1 & 3 & 1 & 7 & $2(w, x)$ \\
\hline Propionate $\ldots \ldots \ldots \ldots$ & 8 & 1 & 1 & $2(k)$ & 1 & $6(o)$ & $3(x)$ \\
\hline Butyrate $\ldots \ldots \ldots \ldots$ & $2(a, b, c, e, g, h)$ & 0 & 0 & 0 & 0 & 0 & 0 \\
\hline$\ldots \ldots \ldots \ldots$ & $2(a, b, c, d, g, h)$ & 2) 0 & 0 & 0 & 0 & 0 & 0 \\
\hline Isovalerate $\ldots \ldots \ldots \ldots \ldots$ & $4(a, b, c, h)$ & 1 & 1 & 0 & 0 & $4(o, p, r)$ & 0 \\
\hline Malonate $\ldots \ldots \ldots \ldots$ & 8 & 1 & 1 & 0 & 1 & 0 & 0 \\
\hline Maleate $\ldots \ldots \ldots \ldots$ & 0 & 0 & 0 & 0 & 0 & $3(o, p, q, t)$ & 0 \\
\hline Adipate $\ldots \ldots \ldots \ldots$ & $6(a, h)$ & 0 & 0 & 0 & 1 & 0 & $2(w, y)$ \\
\hline Pimelate $\ldots \ldots \ldots \ldots$ & $2(a, b, d, e, g, h)$ & ) 0 & 0 & $2(k)$ & 0 & 0 & 4 \\
\hline Suberate $\ldots \ldots \ldots \ldots$ & 8 & 1 & 1 & $1(k, m)$ & 1 & $\begin{array}{l}1(o, p, r, s \\
t, u)\end{array}$ & $3(w)$ \\
\hline Sebacate ........... & 8 & 1 & 1 & $1(k, m)$ & 1 & $\begin{array}{l}2(o, p, r \\
s, t)\end{array}$ & $3(x)$ \\
\hline D-Malate & $3(a, d, e, g, h)$ & 1 & 1 & $2(l)$ & 0 & $5(o, p)$ & 4 \\
\hline$m$-Tartrate & 0 & 0 & 0 & 0 & 0 & $6(p)$ & 0 \\
\hline$\beta$-OH-butyrate $\ldots \ldots \ldots$ & 8 & 1 & 1 & 3 & 1 & $6(p)$ & 4 \\
\hline Lactate ...... & $6(d, f)$ & 1 & 0 & $1(l, m)$ & 1 & $5(p, r)$ & 4 \\
\hline Glycerate $\ldots$. & $\begin{array}{l}2(a, b, c, d \\
\quad f, h)\end{array}$ & 0 & 0 & 0 & 0 & 0 & $2(v, x)$ \\
\hline Hydroxymethyl glutarate .. & $\begin{array}{l}1(a, b, c, d, e, \\
\quad f, g)\end{array}$ & 0 & 0 & 0 & 0 & $\begin{array}{l}1(o, p, q, r \\
\quad s, t)\end{array}$ & 0 \\
\hline Aconitate & $6(b, d)$ & 1 & 1 & 3 & 1 & 7 & 4 \\
\hline Levulinate & 8 & 1 & 1 & 3 & 1 & $5(o, r)$ & $3(x)$ \\
\hline Propylene glycol & $5(e, f, g)$ & 1 & 0 & 0 & 1 & 0 & 0 \\
\hline Erythritol $\ldots \ldots \ldots \ldots$ & 0 & 0 & 0 & 0 & 0 & 7 & 0 \\
\hline$\ldots \ldots \ldots \ldots$ & 0 & 0 & 0 & 0 & 0 & $6(r)$ & 0 \\
\hline$\ldots \ldots \ldots \ldots$ & 0 & 0 & 0 & 0 & 0 & $6(r)$ & 0 \\
\hline$\ldots \ldots \ldots \ldots$ & $3(b, c, d, e, f)$ & 1 & 0 & 0 & 0 & 7 & 0 \\
\hline$m$-Inositol & $7(e)$ & 1 & 1 & $1(k, m)$ & 1 & 7 & 4 \\
\hline Isopropanol $\ldots \ldots \ldots \ldots$ & $\begin{array}{l}1(a, b, c, d, e, \\
\quad g, h)\end{array}$ & 0 & 0 & 0 & 0 & 0 & 0 \\
\hline$n$-Butanol $\ldots \ldots \ldots \ldots \ldots$ & 0 & 0 & 0 & $2(k)$ & 0 & 0 & $2(v, x)$ \\
\hline$p$-OH-benzoate $\ldots \ldots \ldots$ & $6(e, g)$ & 1 & 1 & $1(k, m)$ & 1 & $4(o, p, r)$ & $1(w, x, y)$ \\
\hline Phenylacetate $\ldots \ldots \ldots \ldots$ & $4(a, b, c, h)$ & 0 & 0 & 0 & 0 & 0 & 0 \\
\hline Quinate $\ldots \ldots \ldots \ldots \ldots$ & 0 & 0 & 1 & 0 & 0 & $\begin{array}{c}1(o, p, r \\
\quad s, t, u)\end{array}$ & 4 \\
\hline Glycine & $7(g)$ & 1 & 1 & 3 & 1 & $7^{-2, a)}$ & 4 \\
\hline L-Alanine & 8 & 1 & 1 & 3 & 1 & $6(q)$ & 4 \\
\hline D-Alanine $\ldots \ldots \ldots \ldots$ & $4(c, d, e, g)$ & 0 & 0 & $1(l, m)$ & 1 & $6(s)$ & 4 \\
\hline L-Leucine $\ldots \ldots \ldots \ldots$ & $6(d, f)$ & 1 & 1 & $1(l, m)$ & 1 & $3(o, p, s, t)$ & 4 \\
\hline L-Isoleucine & $7(g)$ & 1 & 1 & $2(k)$ & 0 & $5(o, p)$ & 4 \\
\hline
\end{tabular}


TABLE 2-Continued

\begin{tabular}{|c|c|c|c|c|c|c|c|}
\hline Substrate & $\begin{array}{c}\text { Strains } \\
a \text { to } h^{b} \\
\text { (8 strains) }\end{array}$ & $\begin{array}{l}\text { Strain } i^{b} \\
\text { (1 strain) }\end{array}$ & $\begin{array}{c}\text { S. parvu- } \\
\text { lus } \\
\text { (1 strain) }\end{array}$ & $\begin{array}{c}\text { S. glau- } \\
\text { cescens } \\
\text { (3 strains) }\end{array}$ & $\begin{array}{l}\text { Strain } n^{b} \\
\text { (1 strain) }\end{array}$ & $\begin{array}{c}\text { S. rimosus } \\
\text { (7 strains) }\end{array}$ & $\begin{array}{c}\text { N. mediter } \\
\text { ranei } \\
\text { (4 strains) }\end{array}$ \\
\hline L-Norleucine $\ldots \ldots \ldots \ldots$ & 0 & 0 & 0 & 0 & 0 & 0 & $3(x)$ \\
\hline L-Valine $\ldots \ldots \ldots \ldots \ldots$ & $6(a, h)$ & 1 & 1 & 3 & 1 & 7 & 4 \\
\hline L-Aspartate & 8 & 1 & 1 & 3 & 1 & $6(q)$ & 4 \\
\hline D-Aspartate & $4(b, d, f, g)$ & 1 & 0 & 0 & 1 & 0 & $2(v, y)$ \\
\hline D-Glutamate $\ldots \ldots \ldots$ & $6(e, g)$ & 0 & 0 & 0 & 1 & $\begin{array}{c}1(p, q, r, s, \\
t, u)\end{array}$ & 4 \\
\hline L-Asparagine $\ldots \ldots \ldots \ldots$ & $7(h)$ & 1 & 1 & 3 & 1 & 7 & 4 \\
\hline L-Lysine $\ldots \ldots \ldots \ldots \ldots$ & 8 & 1 & 1 & $2(m)$ & 0 & 7 & 4 \\
\hline L-Citrulline & $3(a, d, e, g, h)$ & 0 & 1 & $2(k)$ & 0 & $4(p, r, s)$ & $3(w)$ \\
\hline$\alpha$-Aminovalerate $\ldots \ldots \ldots$ & 0 & 0 & 0 & 0 & 0 & 0 & $1(w, x, y)$ \\
\hline L-Tyrosine $\ldots \ldots \ldots \ldots \ldots$ & $5(a, d, h)$ & 1 & 1 & $2(m)$ & 1 & 7 & $2(v, w)$ \\
\hline L-Tryptophan $\ldots \ldots \ldots \ldots$ & $\begin{array}{c}1(a, b, c, d, \\
e, g, h)\end{array}$ & 0 & 0 & 0 & 0 & 0 & 4 \\
\hline$\ldots \ldots \ldots$ & $3(a, b, c, d, h)$ & 0 & 1 & 0 & 0 & 0 & 0 \\
\hline Ethanolamine $\ldots \ldots \ldots \ldots$ & 8 & 1 & 1 & $2(k)$ & 0 & 7 & 4 \\
\hline Putrescine $\ldots \ldots \ldots \ldots \ldots$ & 8 & 1 & 1 & $2(m)$ & 1 & $6(r)$ & $1(v, x, y)$ \\
\hline Spermine $\ldots \ldots \ldots \ldots$ & $6(e, g)$ & 1 & 1 & $1(k, m)$ & 1 & 6 & $2(w, x)$ \\
\hline Histamine . . . . . . & $2(b, c, d, e, f, g)$ & 0 & 0 & 0 & 0 & 0 & 0 \\
\hline Betaine . & $2(b, c, d, e, f, g)$ & 0 & 0 & 0 & 0 & 0 & $2(w, x)$ \\
\hline Sarcosine $\ldots \ldots \ldots \ldots \ldots$ & $3(b, c, e, f, g)$ & 0 & 0 & 0 & 0 & $\begin{array}{l}1(p, q, r, s, \\
\quad t, u)\end{array}$ & 4 \\
\hline Hippurate & $3(a, d, e, g, h)$ & 0 & 0 & 0 & 0 & $1 \underset{u)}{1(o, p, r, s, t}$ & $2(w, x)$ \\
\hline Pantothenate .......... & 8 & 1 & 1 & 3 & 1 & 7 & $3(v)$ \\
\hline Acetamide ... & 0 & 0 & 0 & 0 & 0 & $\begin{array}{l}1(o, p, q, s, \\
\quad t, u)\end{array}$ & 0 \\
\hline
\end{tabular}

${ }^{a}$ Numbers of positive strains for each substrate. Negative strains given in parentheses.

${ }^{b}$ See Table 3 for correct identification of strains.

the ability of different species of actinomycetes to utilize carbon compounds for growth. The early method was later changed by various workers mainly with respect to the composition of the basal medium and the precautions recommended to insure a uniform distribution of the inoculum. At present, two different criteria are followed by actinomycete taxonomists for the investigation of the utilization of various lowmolecular-weight organic compounds. Many microbiologists follow the methods used by collaborators of the International Streptomyces Project (12). These methods include the so-called carbon utilization tests in which growth on 10 carbohydrates is determined. Other workers prefer to follow instead the methodology recommended by Gordon (3) in which the change in color of an indicator added to the medium rather than growth is recorded. The two methodologies are not mutually exclusive, and it is therefore surprising that some eclectic temperament has not emerged so far, particularly when the taxonomy of the group is one of the most difficult in the microbial world and microbiologists should, in principle, welcome any well founded source of phenotypic information.

The list of compounds proposed by Gordon includes some organic acids and carbohydrates. The utilization of an organic anion makes the medium more alkaline. A survey on the utilization of six organic acids, based in part on the Gordon methodology, was performed on 118 organisms by Robbel and Kutzner (11). Transformations of sugars generally give an acid reaction to the medium. Both reactions have been used extensively in the identification and classification of other microbial groups, and they are very clear, sensitive, easy to read, and generally very reproducible. The two reactions differ, however, in the type of information that they give. Whereas an alkaline reaction in the medium gives a sensitive indication of the utilization of the organic anion, acid production from sugars is not necessarily correlated with the utilization of the carbon compound. For instance, an organism may be able to oxidize a sugar to a sugar acid without extracting any benefit from the conversion, or it may degrade rather extensively the carbohydrate, producing one or several acids with better chances of utilizing the intermediates for growth. It is true that the practical taxonomist does not need to worry about these complications, since in most cases there is no need of a thorough understanding of the mechanisms underlying the phenotypic traits, as long as the detection and recording of the results are free of ambiguities. There is, however, a serious objection to the value of the test in the possibility of 
oxidation of various aldose sugars to the respective aldonic acids by the same enzymatic system. When used blindly for any collection of aldosugars, the test can therefore yield redundant results in some cases.

One of the few attempts at extensive nutritional characterization of strains of actinomycetes has been the work of Goodfellow (2), who studied the capacity of a large number (102) of carbon compounds to serve as growth substrates of a collection of nocardioform organisms. The methodology presented here for the extensive analysis of nutritional properties of actinomycetes has been found to be quite reliable. Since roughly one-third of the compounds assayed are acids, the method could be further improved by incorporation of an appropriate acid-base indicator to the media containing anionic substrates.

A number of strains do not replicate satisfactorily with the velvet technique of Lederberg and Lederberg (7), and we have not attempted to use it in the present case, since the number of strains under study was small. For larger numbers, it may be possible to speed up considerably the inoculation of the plates by the method of replica plating, using well sporulated master cultures.

Some Streptomyces strains give appreciable growth in agar of mineral media without added carbon sources. Additional growth over this background is often very difficult to judge, although a trained eye can discern growth due to the added carbon source in the great majority of cases. In the group of strains examined by us, $S$. coelicolor strain $a$ presented this problem in its most acute form. Hopwood (5) mentions that this strain [originally designated $\mathrm{A3}(2)$ ] is derived from a group of agar-decomposing organisms studied by Stanier in 1942. For this strain the whole screening was repeated in liquid medium, and the results were essentially the same as those obtained with the solid medium. The only significant discrepancies were in the utilization of D-alanine, D-aspartate, and citrate, all of which gave better growth in solid than in liquid medium. Strain $h$ of this collection is derived from strain $a$, and it is characterized by the inability to decompose agar. Consequently, it only gives a faint marginal growth in our control plates. As indicated in Materials and Methods, the mineral medium for this particular strain has been supplemented with cystine, methionine, and threonine, which satisfy its auxotrophic requirements. This strain has essentially the same nutritional spectrum as its parent strain $a$, although there are a few differences which are apparently unrelated to the properties recorded in its known genotype.

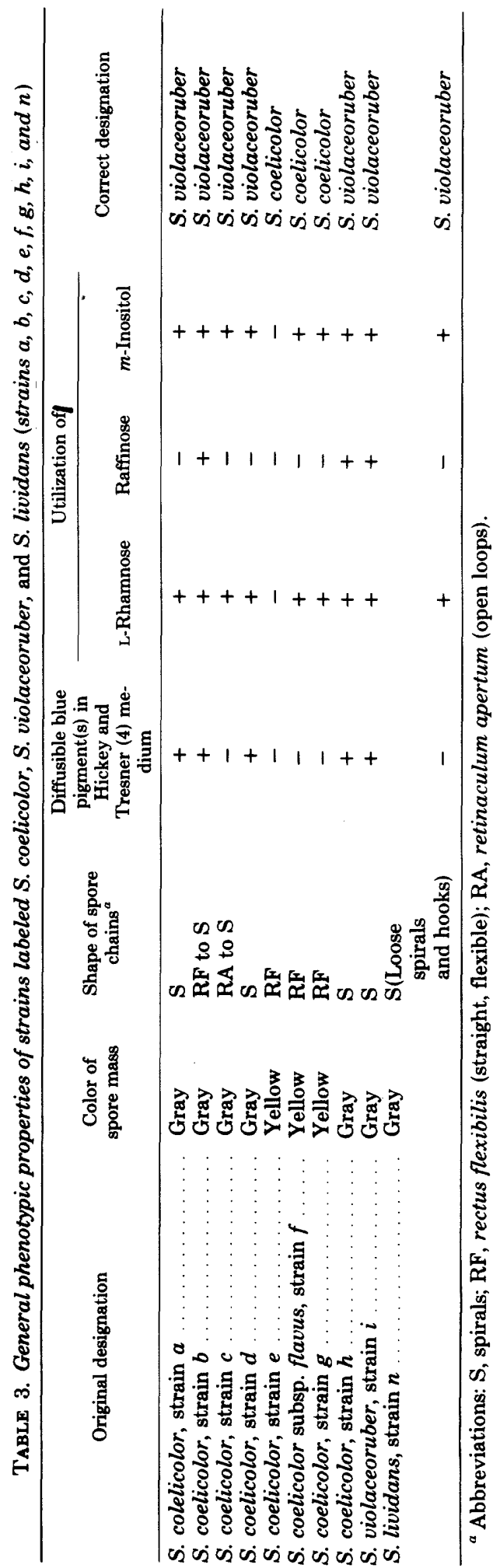


TABLE 4. Substrates of probable taxonomic importance for the differentiation of at least two of the species ${ }^{a}$

\begin{tabular}{|c|c|c|c|c|c|c|}
\hline Substrate & $\begin{array}{c}\text { S. coeli- } \\
\text { color } \\
\text { (3 strains) }\end{array}$ & $\begin{array}{l}\text { S. viola- } \\
\text { ceoruber } \\
\text { (7 strains) }\end{array}$ & $\begin{array}{l}\text { S. parvulus } \\
\text { (1 strain) }\end{array}$ & $\begin{array}{c}\text { S. glau- } \\
\text { cescens } \\
\text { (3 strains) }\end{array}$ & $\begin{array}{l}\text { S. rimosus } \\
\text { (7 strains) }\end{array}$ & $\begin{array}{c}\text { N. mediter- } \\
\text { ranei } \\
\text { (4 strains) }\end{array}$ \\
\hline D-Arabinose $\ldots \ldots \ldots \ldots$ & - & - & - & - & $2 / 7$ & + \\
\hline L-Fucose $\ldots \ldots \ldots \ldots$ & - & - & - & - & $1 / 7$ & + \\
\hline$\ldots \ldots \ldots \ldots \ldots$ & - & - & - & - & $1 / 7$ & + \\
\hline Saccharate ........... & - & $5 / 7$ & + & - & - & $1 / 4$ \\
\hline Malonate . . . . . . . . & + & + & + & - & - & - \\
\hline$\ldots \ldots \ldots \ldots \ldots$ & + & $4 / 7$ & - & - & - & $2 / 4$ \\
\hline Pimelate $\ldots \ldots \ldots \ldots$ & $1 / 3$ & $1 / 7$ & - & $2 / 3$ & - & + \\
\hline Lactate & $2 / 3$ & $6 / 7$ & - & $1 / 3$ & $5 / 7$ & + \\
\hline Propylene glycol & - & + & - & - & - & - \\
\hline Erythritol $\ldots \ldots \ldots \ldots$ & - & - & - & - & + & - \\
\hline Xylitol $\ldots \ldots \ldots \ldots$ & - & - & - & - & $6 / 7$ & - \\
\hline Adonitol & - & - & - & - & $6 / 7$ & - \\
\hline Sorbitol $\ldots \ldots \ldots \ldots \ldots$ & $1 / 3$ & $3 / 7$ & - & - & + & - \\
\hline Quinate .............. & - & - & + & - & $1 / 7$ & + \\
\hline D-Alanine $\ldots \ldots \ldots \ldots$ & $1 / 3$ & $4 / 7$ & - & $1 / 3$ & $6 / 7$ & + \\
\hline D-Glutamate $\ldots \ldots \ldots \ldots$ & $1 / 3$ & $6 / 7$ & - & - & $1 / 7$ & + \\
\hline L-Tryptophan $\ldots \ldots \ldots \ldots$ & $1 / 3$ & - & - & - & - & + \\
\hline Sarcosine $\ldots \ldots \ldots \ldots$ & - & $3 / 7$ & - & - & $1 / 7$ & + \\
\hline
\end{tabular}

${ }^{a}$ Symbols: +, all strains grow; -, no strain grows. When the property is not universal, the fraction of positive strains is given.

The strains examined by us are only moderately versatile, the total number of compounds used for growth ranging from about 50 to nearly 80. The groups of compounds that are most frequently used are the carbohydrates and the amino acids. The utilization of other classes of substrates is rather irregular and, characteristically, many fatty acids, alcohols, aromatic compounds, and miscellaneous nitrogenous compounds did not support growth of any of the strains examined. Some substrates (particularly some aliphatic acids and aromatic compounds) may actually be toxic at the concentration used in the media, as suggested by the inhibition of background growth of strain $a$ when one compares growth on these compounds with that obtained on the unsupplemented mineral agar.

Unpublished results obtained by us on a larger collection of strains of Streptomyces and of other genera of actinomycetes suggest that the nutritional versatility is in general very similar to that of the strains examined here. In comparison, some aerobic pseudomonads, notably some fluorescent organisms and also Pseudomonas cepacia and $P$. pseudomallei, appear to be more versatile $(1,10,13)$. These organisms, which are endowed with a fast growth rate, would predominate in the soil microflora when low-molecularweight organic compounds are being released as a consequence of the hydrolytic activities of other microorganisms, particularly fungi and actinomycetes.

Actinomycetes have a reputation for marked nutritional versatility which is in part supported by the results of our analysis, although it appears rather surprising that some classes of organic compounds that are excellent substrates for other common organisms do not support growth of any of the strains in this collection. Extremely slow growth at the expense of some substrates may be recorded as a negative result in our experiments. It is possible that some substrates may be used when they are present in the medium at higher or lower concentrations than the one used here, or in mixtures with other cometabolizable carbon sources. But it also appears likely that actinomycetes may be able to grow on a number of unusual compounds not normally included in nutritional tests. A large variety of miscellaneous organic molecules resistant to the attack by most other groups of microorganisms, which may be present in natural habitats, and many synthetic compounds may be growth substrates for actinomycetes. Inclusion of these carbon sources in a nutritional screening may be the only way to reveal the nutritional potentiality of the group.

In Table 1 we have named the strains included in the present study according to the designation given to them at the source of origin. The nomenclatural state of several of these strains is at present rather inadequate, and some comments on this point will not be out of place here. The species S. coelicolor and S. violaceoruber can be differentiated by using the criteria discussed by Kutzner and Waksman (6). The most useful characters appear to be the morphology and color of the spore mass, the properties of the pigments produced, and the utilization of Lrhamnose, $m$-inositol, and raffinose as carbon 
sources for growth. An analysis of some of these basic properties for various strains used in our work is given in Table 3 , which also includes the information on S. lividans, a name considered to be a synonym of $S$. violaceoruber. According to data published in the literature, $S$. violaceoruber can be distinguished by the formation of chains of spores with the shape of spirals, by the gray color of the spore mass, and by the utilization of the three carbon sources L-rhamnose, $m$ inositol, and raffinose. Instead, S. coelicolor does not form spirals, produces a spore mass of yellowish color, and does not use any of the three carbon sources. As seen in Table 3 , the diagnoses of strains $b, e, h$, and $i$ is clear-cut. Strains $c, d$, and $n$ form spirals and gray spore masses but are unable to use raffinose, although perhaps this trisaccharide may be used at higher concentrations than the one used in our experiments. Finally, strains $f$ and $g$ have the $S$. coelicolor morphology and pigmentation, but they appear atypical in the capacity of utilization of L-rhamnose and $m$-inositol.

If we accept the designation of these strains as presented in the last column of Table 3, some interesting correlations in nutritional properties are worth discussing. Propylene glycol is a substrate not used by any of the three strains of $S$. coelicolor, and it is used by all the $S$. violaceoruber strains. The $S$. coelicolor strains $e$ and $g$ differ from strain $f$ and from all the $S$. violaceoruber strains in being able to use glucosamine but lacking the capacity of growth on lactobionate, $p$-hydroxybenzoate, and spermine. The behavior of strain $f$, which was received under the designation S. coelicolor subsp. flavus, is rather atypical. In addition to the above differences, it also differs from the other two $S$. coelicolor strains in the utilization of 2-ketogluconate, butyrate, pimelate, D-malate, lactate, glycerate, isopropanol, $\mathrm{D}$-alanine, L-leucine, L-citrulline, $\mathrm{L}$ tryptophan, and hippurate (Table 2). These substrates, however, do not have diagnostic importance for the differentiation of $S$. coelicolor and $S$. violaceoruber.

D-Arabinose, L-fucose, sucrose, and quinate are substrates used by the four strains of Nocardia mediterranei and by relatively few of the Streptomyces strains. Strains of S. rimosus are the only ones in the collection that can grow with $m$-tartrate, erythritol, xylitol, and adonitol. Outside of these exceptional situations, however, no nutritional pattern can be drawn for a clearcut separation of the species. Characters of probable taxonomic significance for the differentia- tion of at least two species are presented in Table 4. Nevertheless, we want to emphasize that our study has been restricted to the examination of relatively few strains that are familiar to geneticists, and therefore it would be pretentious to draw taxonomic conclusions from the results. Without a better knowledge of the intraspecific variability, our data are of limited value for a definition of the nutritional phenotypes of the species involved.

\section{REPRINT REQUESTS}

Address reprint requests: Dr. Norberto Palleroni, Department of Chemical Research, Hoffman-LaRoche Inc., Nutley, NJ 07110.

\section{LITERATURE CITED}

1. Ballard, R. W., N. J. Palleroni, M. Doudoroff, R. Y. Stanier, and M. Mandel. 1970. Taxonomy of the aerobic pseudomonads: Pseudomonas cepacia, $P$. marginata, P. alliicola, and P. caryophylli. J. Gen. Microbiol. 60:199-214.

2. Goodfellow, M. 1971. Numerical taxonomy of some nocardioform bacteria. J. Gen. Microbiol. 69:33-80.

3. Gordon, R. E. 1967. The taxonomy of soil bacteria, p. 293-321. In T. R. G. Gray and B. Parkinson (ed.), The ecology of soil bacteria. Liverpool University Press, Liverpool, England.

4. Hickey, R. J., and H. D. Tresner. 1952. A cobalt-containing medium for sporulation of Streptomyces species. J. Bacteriol. 64:891-892.

5. Hopwood, D. A. 1959 . Linkage and the mechanism of recombination in Streptomyces coelicolor. Ann. N.Y. Acad. Sci. 81:887-898.

6. Kutzmer, H. J., and S. A. Waksman. 1959. Streptomyces coelicolor Müller and Streptomyces violaceoruber Waksman and Curtis, two distinctly different organisms. J. Bacteriol. 78:528-538.

7. Lederberg, J., and E. M. Lederberg. 1952. Replica plating and indirect selection of bacterial mutants. J. Bacteriol. 63:399-406.

8. Palleroni, N. J., and M. Doudoroff. 1972. Some properties and taxonomic subdivisions of the genus Pseudomonas. Annu. Rev. Phytopathol. 10:73-100.

9. Pridham, T. G., and H. D. Tresner. 1974. Family VII. Streptomycetaceae Waksman and Henrici 1943, 339, p. 747-845. In R. E. Buchanan and N. E. Gibbons (ed.), Bergey's manual of determinative bacteriology, 8th ed. The Williams \& Wilkins Co., Baltimore.

10. Redfearn, M. S., N. J. Palleroni, and R. Y. Stanier. 1966. A comparative study of Pseudomonas pseudomallei and Bacillus mallei. J. Gen. Microbiol. 43:293-313.

11. Robbel, L., and H. J. Kutzmer. 1973. Streptomyces taxonomy: utilization of organic acids as an aid in the identification of species. Naturwissenschaften 60:351-352.

12. Shirling, E. B., and D. Gottlieb. 1966. Methods for the characterization of Streptomyces species. Int. J. Syst. Bacteriol. 16:313-340.

13. Stanier, R. Y., N. J. Palleroni, and M. Doudoroff. 1966. The aerobic pseudomonads: a taxonomic study. J. Gen. Microbiol. 43:159-271.

14. Waksman, S. A. 1961. The actinomycetes, vol. 1. The Williams and Wilkins Co., Baltimore. 